\title{
The physical state of a meal affects hormone release and postprandial thermogenesis
}

\author{
Maddalena Peracchi ${ }^{1}$, Alessandra Santangelo ${ }^{2}$, Dario Conte $^{1}$, Mirella Fraquelli ${ }^{1}$, Rosalia Tagliabue ${ }^{1}$, \\ Carlotta Gebbia ${ }^{1}$ and Marisa Porrini ${ }^{2}$ \\ ${ }^{1}$ Department of Gastroenterology, Institute of Medical Science, University of Milan, Ospedale Maggiore-IRCCS, \\ via F. Sforza 35, 20122 Milan, Italy \\ ${ }^{2}$ Department of Food Science and Technology, Nutrition Section, University of Milan, via Celoria 2, 20133 Milan, Italy
}

(Received 25 May 1999 - Revised 11 October 1999 - Accepted 8 November 1999)

\begin{abstract}
There is evidence that food consistency may influence postprandial physiological responses. Recently we found that homogenization of a vegetable-rich meal significantly delayed the gastric emptying rate and was more satiating than the same meal in solid-liquid form. In this present study we investigated whether homogenization also influences endocrine and metabolic responses to the meal. Eight healthy men, aged 21-28 (mean 24.5) years, were given the meal (cooked vegetables $250 \mathrm{~g}$, cheese $35 \mathrm{~g}$, croutons $50 \mathrm{~g}$ and olive oil $25 \mathrm{~g}$, with water $300 \mathrm{ml}$; total energy 2.6 MJ) in both solid-liquid (SM) and homogenized (HM) form, in random order, at 1week intervals. Variables assayed were plasma glucose, insulin and glucose-dependent insulinotropic peptide (GIP) levels for $2 \mathrm{~h}$ and diet-induced thermogenesis (DIT) for $5 \mathrm{~h}$. Plasma glucose pattern was similar after both meals. However, HM induced significantly greater insulin, GIP and DIT responses than SM. Mean integrated areas under the curves (AUC) were 1.7 (SEM 0.38) v. 1.2 (SEM 0.33) U/l per $120 \mathrm{~min}(P=0.005)$ for insulin, 19.9 (SEM 2.44) $v .16$ (SEM 1.92) nmol/l per $120 \mathrm{~min}(P=0.042)$ for GIP, and 237.7 (SEM 16.32) $v$. 126.4 (SEM 23.48) kJ/300 $\mathrm{min}(P=0.0029)$ for DIT respectively. Differences between GIP-AUC after HM and SM correlated significantly with differences between insulin-AUC after HM and SM $\left(r^{2} 0.62, P=0.021\right)$. These findings demonstrate that homogenization of a meal results in a coordinated series of changes of physiological gastroentero-pancreatic functions and confirm that the physical state of the meal plays an important role in modulating endocrine and metabolic responses to food.
\end{abstract}

Food consistency: Glucose-dependent insulinotropic peptide: Insulin: Diet-induced thermogenesis

Physical and chemical properties of foods modulate the absorption and metabolism of nutrients by influencing both the gastric emptying rate and the release of gut hormones and neurotransmitters (Schirra et al. 1996). Thus, in nondiabetic subjects, glycaemic and insulinaemic responses to meals depend not only on the quantity of carbohydrate consumed but also on its source (Wolever \& Bolognesi, 1996), and are modified by the concomitant presence of other macronutrients (Joannic et al. 1997). Indeed, several studies have shown that the association of protein, fat or fibre with carbohydrate can reduce the postprandial glucose response (Estrich et al. 1967; Collier et al. 1984; Gulliford et al. 1989; Torsdottir et al. 1989). Moreover, manipulations of starch, including cooking, cooling, changes in its viscosity and osmolality, and chemical modifications, can influence its glycaemic and/or insulinaemic index, and starch usually contributes over $50 \%$ of all carbohydrate in a mixed meal (Würsch, 1989; Björck, 1996; Raben et al. 1997).

Insulin plays a key role in the control of energy balance by promoting storage of ingested nutrients. However, there is some evidence that insulin may act at the level of the central nervous system, inhibiting food intake and stimulating thermogenesis (Rothwell, 1992). In addition, Landsberg \& Young (1983) postulated that a meal resulting in relatively high postprandial insulin response may increase the facultative part of diet-induced thermogenesis (DIT) via stimulation of the sympathetic nervous system. Holt et al. (1996) reported that foods producing a higher postprandial insulin response were associated with less subsequent food intake and thus indirectly with greater satiety.

We recently found that homogenization of a fat-rich and vegetable-rich meal significantly delayed the gastric

\footnotetext{
Abbreviations: AUC, area under the curve; DIT, diet-induced thermogenesis; GIP, glucose-dependent insulinotropic peptide; HM, meal in homogenized form; SM, meal in solid form.

* Corresponding author: Dr Maddalena Peracchi, fax +39 02 55012111, email gastrbia@imiucca.csi.unimi.it
} 
emptying rate in healthy subjects and that such a meal was significantly more satiating than the same meal given in a conventional solid-liquid form (Santangelo et al. 1998). The reasons for these differences are still unclear. Therefore, in this present paper we investigated whether plasma glucose, insulin and glucose-dependent insulinotropic peptide (GIP) responses to the vegetable-rich meal and DIT are influenced by homogenization of the meal.

\section{Materials and methods}

\section{Subjects}

Eight healthy men, aged 21-28 (mean 24.5) years, were recruited for this study which was approved by the local ethics committee. All subjects were within $10 \%$ of ideal body weight, with a BMI of 21-25 (mean $22 \cdot 8$ ) $\mathrm{kg} / \mathrm{m}^{2}$. None of them was a smoker, was taking medication, had a family history of diabetes mellitus, suffered from gastrointestinal symptoms or any systemic disease including diabetes mellitus.

All the subjects underwent a complete endocrine evaluation, with a concomitant energy expenditure assessment in six cases.

\section{Procedures}

The test meal consisted of $(\mathrm{g})$ : cooked vegetables 250 , cheese 35 , croutons 50 and olive oil $25(2.6 \mathrm{MJ}(60 \%$ energy as fat, $27 \%$ energy as carbohydrate, $13 \%$ energy as protein), $8 \mathrm{~g}$ fibre (16\% soluble, $84 \%$ insoluble)) (Santangelo et al. 1998), given either in solid form (SM), with $300 \mathrm{ml}$ of water to drink during the consumption, or homogenized with the addition of the same amount of water (HM).

Subjects were studied twice, at an interval of at least 1 week, with SM and HM given in randomized order. They were instructed to abstain from physical exercise the day before each test and to fast from 22.00 hours the evening before. On the study day the subjects came to the laboratory between 08.30 and 09.30 hours. During the first $15 \mathrm{~min}$ after arrival they rested quietly in the supine position, and a retrograde venous cannula was inserted into the left hand for blood sampling and kept patent by slow saline $(9 \mathrm{~g} \mathrm{NaCl} / \mathrm{l})$ infusion. The BMR was recorded for $30 \mathrm{~min}$. The test meal was then served (time 0) and eaten in $15 \mathrm{~min}$. Postprandial energy expenditure was measured continually for $5 \mathrm{~h}$ with three 20 min breaks. Subjects were instructed to remain awake and immobile during the measurement and were allowed to listen to music. During breaks, they could stand up and move in the laboratory or, if necessary, go to the bathroom. Blood samples were collected in ice-chilled polypropylene tubes containing EDTA $(1 \mathrm{mg} / \mathrm{ml})$ and aprotinin $(500 \mathrm{kIU} / \mathrm{ml})$ at the following times: $-30,0,15,30,45$, 60, 90 and 120 min. Plasma was separated immediately by centrifugation at $3000 \mathrm{~g}$ at $4^{\circ}$ and stored in portions at $-80^{\circ}$ until assayed.

\section{Assays}

Plasma insulin and GIP levels were measured by radioimmunoassay using commercially available kits (Insulin, Biodata SpA, Guidonia Montecelio, Rome, Italy; Gastric inhibitory peptide, Peninsula Laboratories Inc, Belmont,
CA, USA). Before being assayed for GIP, plasma was extracted on Sep Pak $\mathrm{C}_{18}$ cartridges (Waters Corporation, Milford, MA, USA) (Peracchi et al. 1999). The $95 \%$ confidence detection limits were $0.2 \mu \mathrm{U} /$ tube for insulin and $3 \mathrm{pg} / \mathrm{tube}$ for GIP, and the intra- and interassay CV were $4.5 \%$ and $5.7 \%$, and $6.8 \%$ and $9.9 \%$ respectively. Plasma glucose levels were determined by means of a glucose autoanalyser with a hexokinase method (Beckman, Milan, Italy).

Energy expenditure was measured by indirect calorimetry using an open-circuit ventilated-hood system (Deltatrac II, Datex Instrumentarium Corp., Helsinki, Finland). $\mathrm{O}_{2}$ consumption $\left(\mathrm{V}_{\mathrm{O}_{2}}(1 / \mathrm{min})\right)$ and $\mathrm{CO}_{2}$ production $\left(\mathrm{V}_{\mathrm{CO}_{2}}(1 / \mathrm{min})\right)$ were printed out every min, and the mean values for the $30 \mathrm{~min}$ pre-meal measurement period and every $30 \mathrm{~min}$ period after the meal were calculated automatically. At each time point energy expenditure was obtained according to the standard abbreviated Weir (1949) equation. DIT was calculated as the postprandial increase in energy expenditure above the pre-meal values. The within-person day-today $\mathrm{CV}$ of pre-meal energy expenditure was $6 \cdot 1 \%$.

\section{Statistical analysis}

Results were given as means with their standard errors. Postprandial data were computed at each time point by subtracting basal values, and the integrated areas under these curves (AUC) were calculated using the trapezoidal rule. Data were evaluated by a repeated-measures analysis of covariance with time as covariate and type of food (SM or $\mathrm{HM}$ ) as dependent variable; means were compared using the least significant difference test. Student's paired $t$ test was employed to evaluate the difference in AUC values, basal values and peak times. Relationships between variables were assessed by linear regression analysis. $P<0.05$ was considered statistically significant. The computer program STATISTICA for Windows (StatSoft Inc., Tulsa, OK, USA) was used for the analysis.

\section{Results}

Fasting plasma levels of glucose (4.6 (SEM 0.10) v. 4.7 (SEM 0.12) nmol/l), insulin (9.3 (SEM 1.07) v. 10.6 (SEM $0.91) \mathrm{mU} / \mathrm{l}), \mathrm{GIP}$ (22 (SEM 5.4) v. 29 (SEM 4.1) pmol/l) and basal energy expenditure (5.7 (SEM 0.19) v. 5.5 (SEM 0.16) $\mathrm{kJ} / \mathrm{min}$ ) were not significantly different on the two test days.

Postprandial time courses of plasma glucose, insulin and GIP concentrations and their integrated AUC are shown in Fig. 1. There were no significant differences in plasma glucose increments after the SM and HM, although peak times were slightly delayed after the HM (28 (SEM 3.4) v. 24 (SEM 3.9) min, NS). Plasma insulin and GIP responses were significantly higher after the HM compared with the SM, both when the data were expressed as variation over time $\left(F_{(1,54)} 7 \cdot 183, P=0.0097\right.$ and $F_{(1.54)} 13.466, P=0.0006$ respectively) and as AUC ( $t$ 4.053, $P=0.005$ and $t 2.479$, $P=0.042$ respectively).

After the HM, insulin peak levels occurred significantly later than after the SM (41 (SEM 4.7) v. 28 (SEM 3.4) min, $t 2.497, P=0.041$ ) whereas with both meals GIP levels peaked at $30-60 \mathrm{~min}$ and thereafter remained elevated 

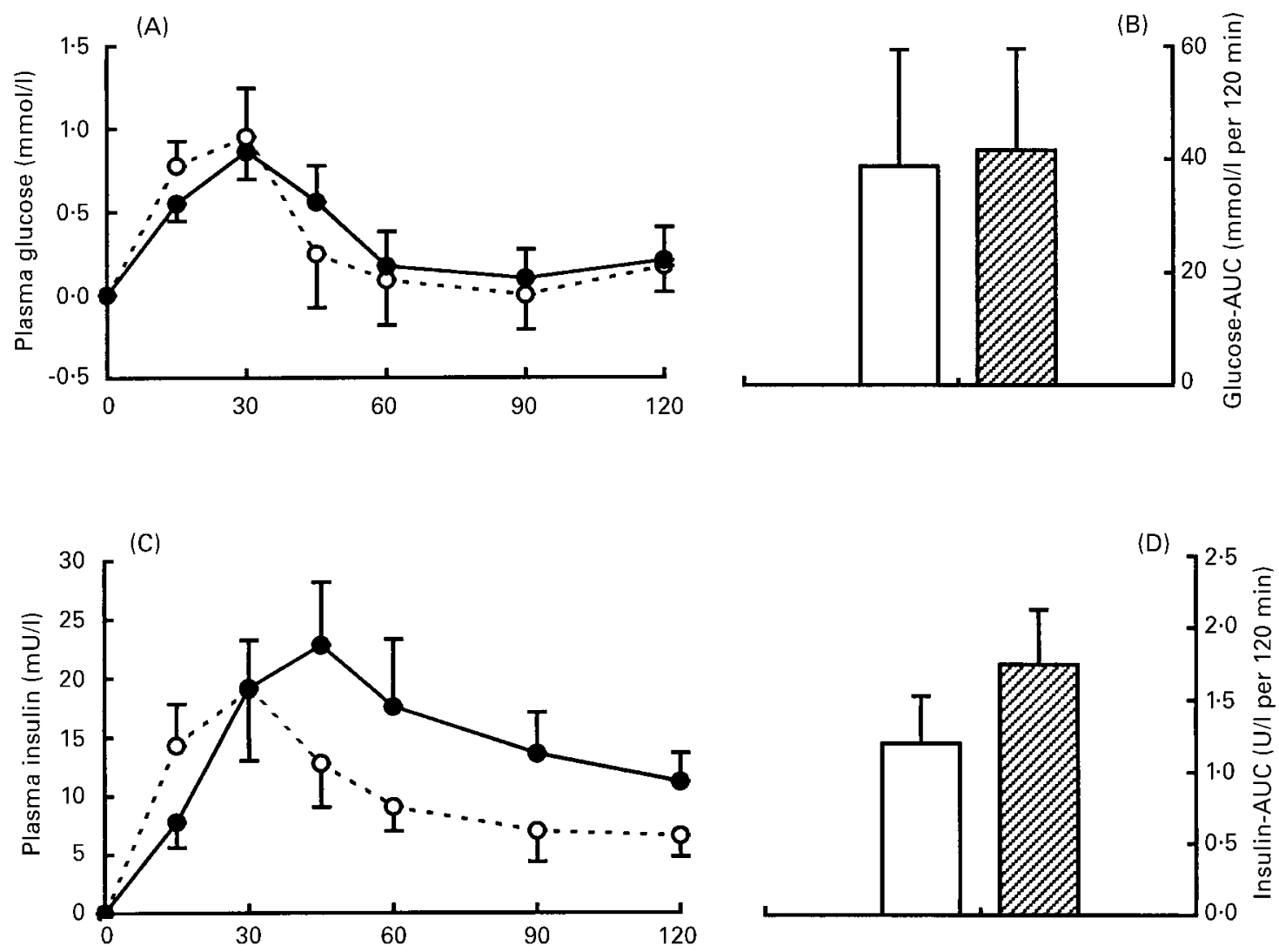

(E)

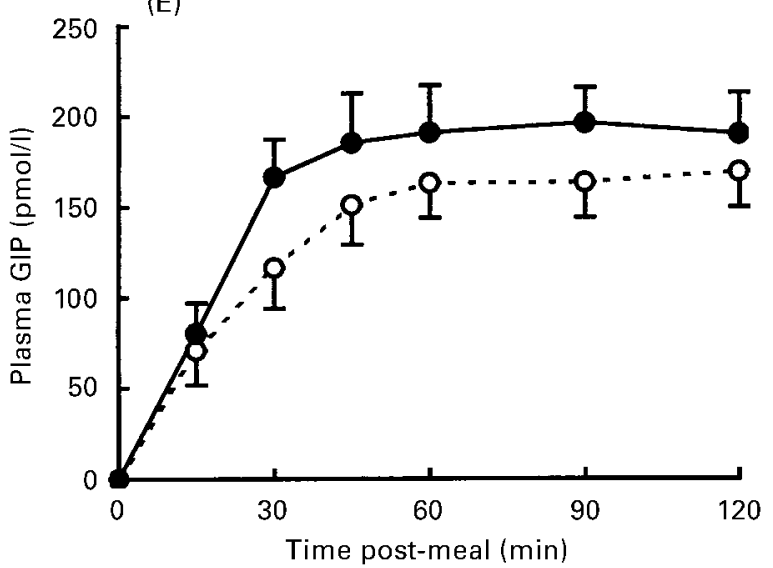

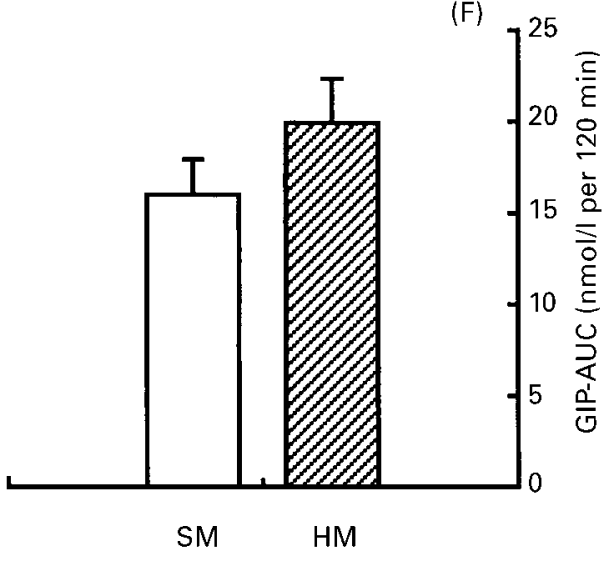

Fig. 1. Plasma glucose ((A), (B)), insulin ((C), (D)), and glucose-dependent insulinotropic peptide (GIP) ((E), (F)) after the solid-liquid (SM; O) and the homogenized meal $(\mathrm{HM} ; \boldsymbol{\bullet})$ in eight healthy men. Results are given as variation from baseline at different time points $((A)$, (C), (E)) and as integrated areas under the curves (AUC) (B), (D), $(F)$ ). Values are means with their standard errors represented by vertical bars. For (C) and (E), mean values after SM were significantly different from those after HM: $P=0.0097, P=0.0006$ respectively (analysis of covariance); for (D) and (F) mean values for SM were significantly different from those after HM: $P=0.005, P=0.042$ respectively (Student's paired $t$ test). For details of meals and procedures see p. 624 .

throughout the study period. With both meals, insulin and glucose peak times correlated significantly $(y=7.295+$ $\left.0.546 x, r^{2} 0.488, P=0.003\right)$ but GIP peak times did not correlate with those of insulin or glucose. However, as shown in Fig. 2, differences between GIP-AUC after the $\mathrm{HM}$ and SM correlated significantly with differences between insulin-AUC after the HM and SM $(y=0.284+$ $0.067 x, r^{2} 0.618, P=0.021$ ).

DIT after the HM was significantly higher than after the SM (Fig. 3), both when the data were expressed as variation over time $\left(F_{(1.58)} 87 \cdot 351, P<0 \cdot 0001\right)$ and as AUC $(t 5 \cdot 394$, $P=0 \cdot 0029)$. Considering only the first $120 \mathrm{~min}$ of recording, 


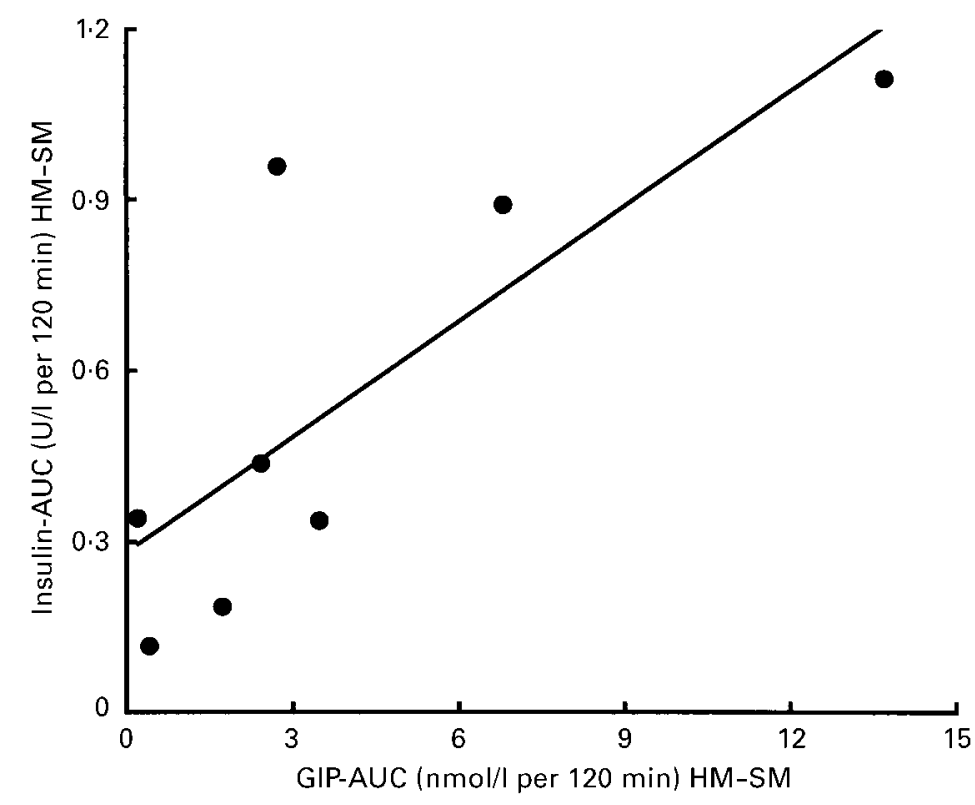

Fig. 2. Correlation between differences in glucose-dependent insulinotropic peptide (GIP) areas under the curve (AUC) after the homogenized (HM) and the solid-liquid meal (SM) and differences in insulin AUC after HM and SM $\left(y=0.284+0.067 x\right.$, SE of estimate $\left.0.255 ; r^{2} 0.618, P=0.021\right)$ in eight healthy men. For details of meals and procedures see p. 624.

(A)

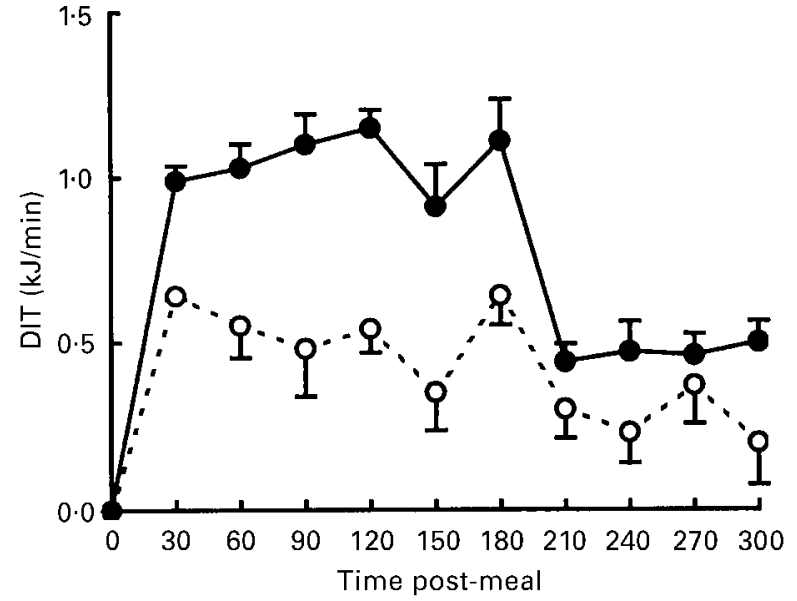

(B)

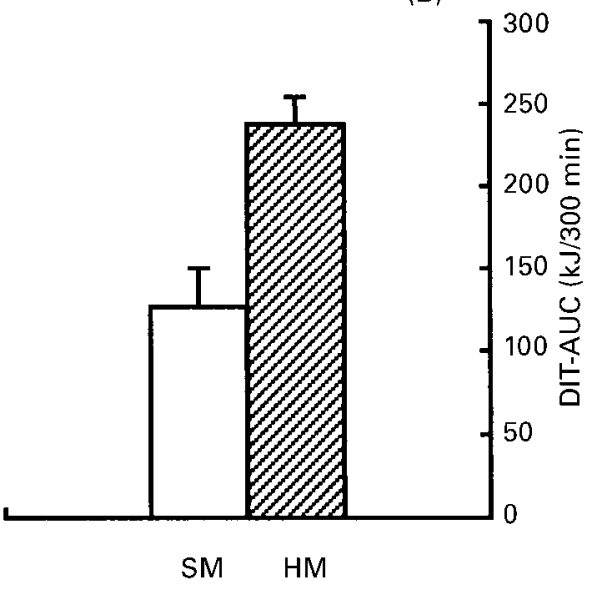

Fig. 3. Diet-induced thermogenesis (DIT) after the solid-liquid (SM; $O)$ and the homogenized meal (HM; $\bullet$ ) in six healthy men. Results are shown as variation from baseline at different time-points (A) and as integrated areas under the curves (AUC) (B). Values are means with their standard errors represented by vertical bars. For (A) mean values after SM were significantly different from those after HM: $P<0.0001$ (analysis of covariance); for (B) mean values for SM were significantly different from those after HM: $P=0.0029$ (Student's paired $t$ test). For details of meals and procedures see p. 624.

the difference was highly significant $\left(F_{(1,22)} \quad 76 \cdot 494, P<\right.$ $0 \cdot 0001)$. Over this $2 \mathrm{~h}$ period mean energy expenditure increase above the basal values was $17 \%(0.92$ (SEM $0 \cdot 16) \mathrm{kJ} / \mathrm{min})$ after the $\mathrm{HM}$ and $9 \%(0.48($ SEM $0 \cdot 18) \mathrm{kJ} /$ min) after the SM.

\section{Discussion}

In this present study insulin and GIP release and DIT were higher after the HM compared with the SM whereas the plasma glucose pattern was similar in the two tests. The positive correlation ( $r$ 0.79) observed between differences in GIP-AUC and insulin-AUC after the two meals underlines the importance of GIP in determining postprandial insulin release. GIP's role as an incretin is well known and depends on a sufficient postprandial increase of circulating glucose levels (Andersen et al. 1978). The role of other incretin hormones, mainly glucagon-like peptide $1(7-36)$ amide is still being investigated (Fehmann et al. 1995; Ørskov et al. 1996; Schirra et al. 1996) and there is evidence that the glycaemic and insulinaemic responses to meals ultimately depend on the integrated interaction of glucose delivery to 
the duodenum, and GIP and glucagon-like peptide 1 (7-36) amide release (Schirra et al. 1996). In the presence of similar glycaemic responses the extent of GIP secretion is usually related to the total energy intake (Beck et al. 1984). However, in this present study we used two isoenergetic, isovolumetric meals which differed only in physical state (HM v. SM). The meal included $250 \mathrm{~g}$ cooked vegetables, which are a good source of dietary fibre. As evidence exists that fibre can modulate the GIP response to a standard meal (Morgan et al. 1990), we may suppose that homogenization of the meal influenced its physical and physiological properties by disrupting the structure of vegetables and fibre (Anderson \& Chen, 1979; Holt \& Miller, 1994; Gustafsson et al. 1995). Interestingly, in line with our previous findings indicating that homogenization delays the gastric emptying time (Santangelo et al. 1998), in this present study glucose and insulin levels peaked later after the HM than after the SM whereas GIP levels peaked 30-60 min after both the HM and SM. This observation is consistent with previous studies showing that GIP release is not directly related to gastric emptying but is governed by intestinal glucose and fat absorption (Fehmann et al. 1995; Schirra et al. 1996). In addition, the half-life of GIP in the circulation is remarkably long, approximately $20 \mathrm{~min}$ (Sarson et al. 1982), and this could well account for the finding that in our subjects GIP levels remained elevated throughout the study period.

On the other hand, it has already been suggested (Fried et al. 1991) that in healthy subjects gastric meal-emptying correlates closely with insulin release. Our results seem to confirm these findings as our HM, which was emptied more slowly than the SM, induced an initially slower postprandial secretion of insulin, which then increased over SM values. Even though we did not measure the early insulin response to the meals, the pattern of insulin release after the HM could suggest a loss of the cephalic phase of postprandial insulin response with a subsequent compensatory hyperinsulinaemia during the digestive phase (Calles-Escandon \& Robbins, 1987). The cephalic phase of insulin release occurs before the nutrient absorption and the rise in arterial glucose levels, and is initiated by sensory stimulation produced by the sight, smell, taste and texture of food (LeBlanc et al. 1991, 1996; Teff et al. 1991). However, there were no differences in the palatability and acceptability scores of HM and SM (Santangelo et al. 1998), even though the texture of the meals was clearly different. On the other hand, the loss of cephalic phase of insulin release is usually associated with blunted DIT (Calles-Escandon \& Robbins, 1987), whereas our results show that the HM caused a higher DIT than the SM. This event could be related to the different pattern of insulin release after the two meals, as insulin is known to participate in the control of facultative DIT component (Landsberg \& Young, 1983). However, we cannot exclude a role for an activation of the sympathetic nervous system and catecholamine release by the different meal textures (LeBlanc et al. 1991).

In addition, Habas \& Macdonald (1998), in their study of isoenergetic high-carbohydrate mixed-nutrient liquid and solid test meals, concluded that the physical form of a test meal affects the physiological responses to nutrient ingestion. However, they found that postprandial energy expenditure (measured for $2 \mathrm{~h}$ after the meals), blood glucose and serum insulin concentrations were significantly higher after the solid meal. The discrepancy with our present results could depend on the completely different food composition of the two meals used by them (liquid meal: semi-skimmed milk, glucose polymer, a powdered protein and double cream; solid meal: cereal, semi-skimmed milk, toasted white bread, jam, butter and white sugar) and, furthermore, on the absence of food rich in fibre in the liquid meal.

Finally, as we have previously found that the vegetablerich meal was significantly more satiating when homogenized, and homogenization increases GIP release, it is interesting that some lines of evidence suggest that GIP and other incretin hormones could modulate appetite control in animals and humans (Flatt et al. 1984; Raben et al. 1996; Lavin et al. 1998; Näslund et al. 1998).

In conclusion, the present findings confirm that the physical state of the meal has an important role in metabolic responses to food.

\section{Acknowledgements}

This study was supported in part by MURST and by Associazione Amici della Gastroenterologia del Padiglione Granelli, Milan, Italy.

\section{References}

Andersen DK, Elahi D, Brown JC, Tobin JD \& Andres R (1978) Oral glucose augmentation of insulin secretion. Interactions of gastric inhibitory polypeptide with ambient glucose and insulin levels. Journal of Clinical Investigation 62, 152-161.

Anderson JW \& Lin Chen WJ (1979) Plant fiber. Carbohydrate and lipid metabolism. American Journal of Clinical Nutrition 32, 346-363.

Beck B, Villaume C, Chayvialle JA, Gariot P, Ulmer M, Desalme A \& Debry G (1984) Influence of caloric intake on gastric inhibitory polypeptide, VIP and gastrin release in man. Peptides 5, 403-406.

Björck I (1996) Starch: nutritional aspects. In Carbohydrates in Food, pp. 505-553 [AC Eliasson, editor]. New York, NY: Marcel Dekker Inc.

Calles-Escandon J \& Robbins DC (1987) Loss of early phase of insulin release in humans impairs glucose tolerance and blunts thermic effect of glucose. Diabetes 36, 1167-1172.

Collier G, McLean A \& O'Dea K (1984) Effect of co-ingestion of fat on the metabolic responses to slowly and rapidly absorbed carbohydrates. Diabetologia 26, 50-54.

Estrich D, Ravnik A, Schlierf G, Fukayama G \& Kinsell L (1967) Effects of co-ingestion of fat and protein upon carbohydrateinduced hyperglycemia. Diabetes 16, 232-237.

Fehmann HC, Göke R \& Göke B (1995) Cell and molecular biology of the incretin hormones glucagon-like peptide-I and glucose-dependent insulin releasing polypeptide. Endocrine Reviews 16, 390-410.

Flatt PR, Bailey CJ, Kwasowski P, Page T \& Marks V (1984) Plasma immunoreactive gastric inhibitory polypeptide in obese hyperglycemic (ob/ob) mice. Journal of Endocrinology 101, 249-256.

Fried M, Schwizer W, Beglinger C, Keller U, Jansen JB \& Lamers CB (1991) Physiological role of cholecystokinin on postprandial insulin secretion and gastric meal emptying in man. Studies with the cholecystokinin receptor antagonist loxiglumide. Diabetologia 34, 721-726. 
Gulliford MC, Bicknell EJ \& Scarpello JH (1989) Differential effect of protein and fat ingestion on blood glucose responses to high- and low-glycemic-index carbohydrates in non insulindependent diabetic subjects. American Journal of Clinical Nutrition 50, 773-777.

Gustafsson K, Asp NG, Hagander B \& Nyman M (1995) Satiety effects of spinach in mixed meals: comparison with other vegetables. International Journal of Food Sciences and Nutrition 46, 327-334.

Habas ME \& Macdonald IA (1998) Metabolic and cardiovascular responses to liquid and solid test meals. British Journal of Nutrition 79, 241-247.

Holt SHA, Brand Miller JC \& Petocz P (1996) Interrelationships among postprandial satiety, glucose and insulin responses and changes in subsequent food intake. European Journal of Clinical Nutrition 50, 788-797.

Holt SHA \& Miller B (1994) Particle size, satiety and the glycaemic response. European Journal of Clinical Nutrition 48, 496-502.

Joannic JL, Auboiron S, Raison J, Basdevant A, Bornet F \& GuyGrand B (1997) How the degree of unsaturation of dietary fatty acids influences the glucose and insulin responses to different carbohydrates in mixed meals. American Journal of Clinical Nutrition 65, 1427-1433.

Landsberg L \& Young JB (1983) The role of the sympathetic nervous system and catecholamines in the regulation of energy metabolism. American Journal of Clinical Nutrition 38, 10181024.

Lavin JH, Wittert GA, Andrews J, Yeap B, Wishart JM, Morris HA, Morley JE, Horowitz M \& Read NW (1998) Interaction of insulin, glucagon-like peptide 1 , gastric inhibitory polypeptide, and appetite in response to intraduodenal carbohydrate. American Journal of Clinical Nutrition 68, 591-598.

LeBlanc J, Diamond P \& Nadeau A (1991) Thermogenic and hormonal responses to palatable protein and carbohydrate rich food. Hormone and Metabolic Research 23, 336-340.

LeBlanc J, Soucy J \& Nadeau A (1996) Early insulin and glucagon responses to different food items. Hormone and Metabolic Research 28, 276-279.

Morgan LM, Tredger JA, Wright J \& Marks V (1990) The effect of soluble- and insoluble-fibre supplementation on postprandial glucose tolerance, insulin and gastric inhibitory polypeptide secretion in healthy subjects. British Journal of Nutrition $\mathbf{6 4}$ $103-110$.

Näslund E, Gutniak M, Skogar S, Rössner S \& Hellström PM (1998) Glucagon-like peptide 1 increases the period of postprandial satiety and slows gastric emptying in obese men. American Journal of Clinical Nutrition 68, 525-530.
Ørskov C, Wettergren A \& Holst JJ (1996) Secretion of the incretin hormones glucagon-like peptide- 1 and gastric inhibitory polypeptide correlates with insulin secretion in normal man throughout the day. Scandinavian Journal of Gastroenterology 31, 665-670.

Peracchi M, Basilisco G, Tagliabue R, Terrani C, Locati A, Bianchi PA \& Velio P (1999) Postprandial gut peptide plasma levels in women with idiopathic slow-transit constipation. Scandinavian Journal of Gastroenterology 34, 25-28.

Raben A, Andersen K, Karberg MA, Holst JJ \& Astrup A (1997) Acetylation of or $\beta$-cyclodextrin addition to potato starch: beneficial effect on glucose metabolism and appetite sensations. American Journal of Clinical Nutrition 66, 304-314.

Raben A, Holst JJ, Christensen NJ \& Astrup A (1996) Determinants of post-prandial appetite sensations: macronutrient intake and glucose metabolism. International Journal of Obesity 20 , 161-169.

Rothwell NJ (1992) Hypothalamus and thermogenesis. In Energy Metabolism: Tissue Determinants and Cellular Corollaries, pp. 229-245 [JM Kinney and HN Tucker, editors]. New York, NY: Raven Press Ltd.

Santangelo A, Peracchi M, Conte D, Fraquelli M \& Porrini M (1998) Physical state of meal affects gastric emptying, cholecystokinin release and satiety. British Journal of Nutrition $\mathbf{8 0}$, 521-527.

Sarson DL, Hayter RC \& Bloom SR (1982) The pharmacokinetics of porcine glucose-dependent insulinotropic polypeptide (GIP) in man. European Journal of Clinical Investigation 12, 457-461.

Schirra J, Katschinski M, Weidmann C, Schäfer T, Wank U, Arnold R \& Göke B (1996) Gastric emptying and release of incretin hormones after glucose ingestion in humans. Journal of Clinical Investigation 97, 92-103.

Teff KL, Mattes RD \& Engelman K (1991) Cephalic phase insulin release in normal weight males: verification and reliability. American Journal of Physiology 261, E430-E436.

Torsdottir I, Alpsten M, Andersson H \& Einarsson S (1989) Dietary guar gum effects on postprandial blood glucose, insulin and hydroxyproline in humans. Journal of Nutrition 119, 19251931.

Weir JBDeV (1949) New method for calculating metabolic rate with special reference to protein metabolism. Journal of Physiology 109, 1-9.

Wolever TMS \& Bolognesi C (1996) Source and amount of carbohydrate affect postprandial glucose and insulin in normal subjects. Journal of Nutrition 126, 2798-2806.

Würsch P (1989) Starch in human nutrition. World Review of Nutrition and Dietetics 60, 199-256. 